\title{
Research on management measures of civil air transportation cost
}

\section{Zhang Guoxia}

\author{
Guangzhou civil aviation college, Guangdong, Guangzhou 510403
}

Key words: civil aviation; transportation cost; present situation; management measure

\begin{abstract}
In recent years, China's civil aviation industry achieved rapid development, the market scale is expanding constantly, enterprises are facing severe market competition, the civil aviation transportation industry economic benefit in the promotion, but their relatively large fluctuations of the profit. The reason for this problem is that the price of crude oil is constantly rising, and the cost of aircraft maintenance is very expensive and consumes a great deal of human resources. Railway operation efficiency in the promotion, people will consider rail travel more, the development of foreign aviation industry rapidly, directly led to China's civil aviation transportation industry has some limitations in the development process, operating efficiency is not ideal. This paper analyzes the current status of civil aviation transportation, combined with the relevant management experience, effectively reduce the cost of civil aviation transportation, to ensure that the civil aviation can better adapt to the development of the market, provide more convenience for travelers.

Now, the development of civil aviation industry is relatively fast, and has entered a new period of development. Civil aviation transportation enterprises, while developing rapidly, are also facing fierce competition from their counterparts. So, civil aviation enterprises should change the traditional business philosophy, not only to the pursuit of economic benefit, but also to improve the quality of service, to achieve the economic growth mode transformation of enterprises, to ensure the operation benefits of continuous improvement, make the enterprise from extensive management into intensive management mode, to ensure the effective management of cost management in.
\end{abstract}

\section{Status quo of cost control of civil aviation transportation in China}

In recent years, China's civil aviation industry has developed steadily, and its development rate is only behind the United States, and has become the world's second. With the development of civil aviation, our country began to rely too much on kerosene. Our country's fuel consumption is very large. The kerosene used in our civil aviation is generally imported. Now the price of international crude oil fluctuates very much, which has a bad influence on the development of civil aviation transportation in our country. But the income of the airport was analyzed, the oil price could not bring more profits to the airport, the airport can not be many economic benefits increased, especially some small and medium enterprises, the location of their business objectives is very high, resulting in the actual development goals and the operation of the market do not coincide, blindly pursue the transportation production scale, but ignore the capacity investment, in the blind pursuit of the scale of production at the same time, enterprises can not carry out the scientific management of cost, resulting in soaring production costs, the rate has exceeded the company's transportation productivity growth rate, resulting in a great discrepancy between the income and transport theory[1]. 


\section{Civil aviation transportation cost control problems}

In civil aviation, $70 \%$ of the transport costs are direct operating costs, and the cost of direct operations is $80 \%$ of the cost of kerosene.

China's fuel prices are serious in monopolistic pricing process, although China's fuel is generally imported, but only a Chinese fuel company, so, although the international crude oil prices on the decline, but the airline still cannot get preferential. In order to enhance the stability of the market, China aviation oil has not combined with world crude oil prices to reduce the price of jet fuel. In our country, the price of jet fuel is usually supplied by ex factory price. After the factory price is determined by the State Planning Commission, the price of China aviation oil will be determined as the selling price. In this kind of policy, although the price of aviation oil of our country is in adjustment, but the price of our country aviation oil still compares foreign jet oil the price is higher.

Through the analysis of the macro development plan of our country, the aviation fuel of civil aviation enterprises adopts the mode of unified supply, and on this basis, maintain the steady development of China's aviation industry. But the civil aviation transportation cost control should proceed from the microscopic angle, and should combine the actual situation of the enterprise. But now a lot of civil aviation enterprises in cost management are blind, a lot of civil aviation in the process of development, can establish and improve the awareness of market competition, so in the cost management, to ensure the scientific management consciousness, in order to enhance their market competitiveness, they blindly expand the scale of production, accounting for not the cost of the enterprise. Second, the enterprise has great limitations in terms of cost management, a lot of civil aviation enterprise transportation task is very heavy, can not achieve timely communication between the various departments, leading to information unobstructed degree is very poor, the control unit can not be timely analysis of the weather and the tower, not the actual situation promptly notify the dispatch. To dispatch, the fuel consumption, production resources to produce a lot of waste, directly lead to imbalance between revenue and cost problem[2].

Through statistical analysis, Chinese aviation transportation enterprises, liabilities of assets is very common, the transportation cost per hour to occupy the entire financial cost around 15-35\%, resulting in capital costs and financial costs very much, have a very big risk in the market.

China's civil aviation passenger occupancy rate is only about $68 \%$, we can see that the transport process led to the rise in costs, transportation in the production efficiency is very low, and the allocation of fixed costs is very large.

The selection of China air transport enterprise is very complex, in addition to small aviation enterprises with single type, medium and large airlines generally use three types of the aircraft, and boat material reserve style is too complicated, leading to the middle link students purchase very large cost models[3].

In the civil aviation transport links, ground support facilities is not particularly perfect, but also has special features, so the money very much, but now ground support facilities China air transport enterprises are very expensive, many enterprises have adopted the form of loans purchased, the production scale is small, the production efficiency is very low. The asset utilization rate is very low, the lack of effective analysis of the economic situation, enterprises will purchase a large number of facilities, resulting in capital occupied.

The influence of the planned economic management, civil aviation transportation enterprises in the seat management is not scientific, and can not meet the market demand in the price management, not by the coordination mechanism based on market changes, but the price of many flights is not flexible enough, the very low flight load factor. Sometimes, enterprises will blindly reduce the price 
of flights, resulting in their economic benefits are not high[4].

\section{Civil aviation transportation cost management measures}

Now, great changes have taken place in the civil aviation transportation market, already from the previous seller's market into a buyer's market, the development potential and market under the conditions of limited resources, to improve the cost management, reduce transportation cost, improve the business efficiency, but also promote the stable development of air transport industry to a certain extent.

The Civil Aviation Administration every year for the completion of the civil aviation transport situation and transportation situation, for the task of civil air transport enterprise for half year, civil aviation should be combined with their completion of the annual index, establish scientific index, and make the income index.

The core of the civil aviation industry is to ensure the safety of air transport, and civil aviation transport enterprises can only achieve better economic and social benefits by ensuring the safety of the transport business. The safety of air transportation has a great influence on the quality of civil aviation transportation enterprises. Adopting the cost leadership strategy can ensure that the enterprises provide all kinds of good service to passengers and control the cost effectively, so that they can compete with their competitors and perfect the Countermeasures for competition. Now, the market has become a buyer's market, the market of each enterprise's competition is very intense, on the same route for passenger services provided by enterprises alike, companies should take advantage of cost management, in order to obtain more profits in the competition, can make passengers more trust in yourself, in order to occupy more market share in the market on. Many foreign civil aviation enterprises have already determined the cost leading strategy, and adopted the scientific way to control the cost. China's Shandong airlines and Shanghai Airlines's profitability is very good, the company has developed a sound cost leadership strategy, the cost of improved control[5].

Civil aviation transportation enterprises should improve the means of publicity, so that employees are fully aware that if not reasonable control costs, will lead to lower economic benefits, make them fully aware of the importance of cost control. On the one hand, the enterprise should establish the number of posts, to ensure that the excess personnel can be assigned to other departments. Second, the people should be strictly controlled, develop into the process of science. Third, we should fully employ market-oriented labor system, and the salary of employees should be in line with the market. Improve the professional quality of employees, the use of market-oriented labor system, control the cost of labor.

Civil aviation transport enterprises should improve the fleet structure, reduce the number of models, so as to ensure that the models show economic characteristics. In the reserve of aviation materials, we should improve the efficiency of work, ensure the sufficient investment of funds and the rational allocation of personnel, so as to effectively reduce costs. In terms of reducing operating costs, efforts should be made to increase the utilization of aircraft. Because the fixed cost of the aircraft will not change, so the higher the utilization of aircraft, then the lower the cost. There are many civil aviation enterprises abroad, and they are taking scientific measures to improve the efficiency of aircraft use. To conduct regular inspection of the aircraft, to prevent malfunctions of the aircraft, because the aircraft maintenance cost is very high, in the arrangement of links in order of flight, should achieve flight, to provide high-quality internal conditions for passengers. The enterprise should communicate effectively with customs and airport, provide external conditions for the effective use of the aircraft, concentrate all the manpower, material and financial resources, 
shorten the time of aircraft ground special, so we can get more economic benefits.

To improve the reserve capacity of aviation materials, $70 \%$ of the air operating costs are direct operating costs, so direct operational costs should be rationally controlled. By optimizing the routes, we can save fuel consumption, improve the maintenance level, can improve the service life of aircraft, and through effective way to prevent the emergence of import monopoly. In the airline's inventory assets, the aircraft material storage occupies the vast majority, therefore, to improve the management of the air material and improve the service life of the material, it is necessary to ensure the dynamic inventory of the aircraft.

Capital refers to the input of the means of production used by enterprises in production or management, and capital has different sources, mainly equity capital and long-term liabilities. Capital structure refers to the dynamic balance between equity, capital and liabilities. There should be a proper proportion between the two, so that enterprises can improve their capital structure.

Debt is an important way to adjust the cost rate of capital in the process of enterprise operation. When the enterprise starts borrowing, it will have serious financial risk. In the actual business process, enterprises can improve the capital structure by means of financial analysis and cash flow. The method of differential analysis is to use different ways to raise funds, analyze the utilization of funds in different ways, so as to find the most reasonable financing methods and optimize the capital structure of enterprises. Cash flow analysis refers to the analysis of the internal capital flow in the case of asset depreciation, so as to reasonably analyze the solvency of the enterprise[6].

The debt structure of civil aviation transportation enterprises combines the proportion between long-term debt and short-term debt. The capital cost of long-term debt will be very high, but the risk can be controlled. If the short-term debt is adopted, the cost of the fund can be controlled, but the risk can not be controlled. Therefore, we should improve the proportion of the two, so that enterprises get different economic benefits. There are many factors affecting the debt structure of civil aviation, and the fixed assets of civil aviation transportation enterprises are very large, so the structure of assets is not conducive to the short-term solvency of enterprises. Moreover, the liquidity of the airline's liquidity is also very different, so the long-term debt situation is more, and it can effectively avoid the risk of enterprises.

To avoid the link in the debt structure of an enterprise, not only to the individual indicators are analyzed, and the comprehensive ability should consider enterprise's assets structure and profitability, so as to establish a comprehensive index. The ratio of liquidity can more scientifically reflect the ability of enterprises to withstand the devaluation of current assets and short-term solvency, and the higher the liquidity ratio, the longer the long-term liabilities of enterprises, the more operating costs of enterprises. If the ratio of the current assets of the enterprise is lower. Under normal circumstances, inventory is the liquidity of the enterprise's liquidity is poor, but also the risk of assets, so in the analysis of the solvency of the enterprise, the use of quick ratio to measure the best results. Great changes do not occur in the civil aviation enterprise's profit level, the inventory turnover days shorter, so enterprise's profit ability is stronger, in this case, the enterprise can use the current liabilities of investment, reduce the cost, improve the income of the enterprise. Epilogue:

Now, our country has entered a period of rapid development, all walks of life have achieved rapid development, and the social division of labor is very clear, the enterprise should combine its own factors and market factors, improve their management ability.

\section{References:}

[1]Reggiani A, Nijkamp P, Cento A. Connectivity and concentration in airline networks: a 
complexity analysis of Lufthansa's network[J]. European Journal of Information Systems, 2010, 19(4):449-461.

[2]Goldstein H. The Role of Knowledge Infrastructure in Regional Economic Development: The Case of the Research Triangle[J]. Canadian Journal of Regional Science, 2005, 28(4):783-90.

[3]Pezzoli K. Environmental Management Systems (EMSs) and Regulatory Innovation[J]. California Western Law Review, 2000, 36:335-365.

[4]Lucas K, Mattioli G, Verlinghieri E, et al. Transport poverty and its adverse social consequences[J]. Transport, 2016.

[5]Welfle A, Gilbert P, Thornley P. Increasing biomass resource availability through supply chain analysis[J]. Biomass \& Bioenergy, 2014, 70:249-266.

[6]Guidotti T L, Calhoun T, Daviescole J O, et al. Elevated lead in drinking water in Washington, DC, 2003-2004: the public health response.[J]. Environmental Health Perspectives, 2007, 115(5):695-701. 